\title{
Leveraging on Industrial and Occupational Safety to Enhance the Dwindled National Economy After Ravages Done by COVID-19 Pandemic
}

\author{
${ }^{1}$ Osuchukwu, C.L., ${ }^{2}$ Meremikwu, B,C., ${ }^{3}$ Obaseki, E., ${ }^{4}$ Onuoha, B \& 5 Unuogu, C.C. \\ 1,2,3,4Department of Mechanical Engineering Technology, Imo State Polytechnic Umuagwo, Owerri \\ ${ }^{3}$ Department of Mechanical Engineering Technology, Federal Polytechnic Nekede \\ ${ }^{5}$ Comprehensive Secondary School Ngugo Imo State. \\ E-mails: 1chimabertdon@gmail.com, ${ }^{2}$ chinonsomeremikwu@yahoo.com ${ }^{3}$ efoba@yahoo.com \\ Phone: ${ }^{1}+2348035768073,{ }^{2}+2348068426612$
}

\begin{abstract}
This piece of Review tries to remind as many of us that are stake-holders in the business of using science and engineering (Technology) to help man in his everyday work, the necessity of the conscious knowledge and constant application of the rules of Health, Safety and Environment Management System which calls for a holistic corrective and proactive measures that mitigate against the effects of undesirable effects which result from accident. It emphasizes on the need for personnel to be oriented on the rudiments of accident occurrences and preventions which are born out in a rooted knowledge of Hazard identification, analysis control, Risk management and Accident contingency management. The overall interest of this work gears towards awakening individual's with Dos and Don'ts that will be in consonance with the national and international best safety rules and practices especially our local work places.
\end{abstract}

Keywords: Safety, Accident, Hazards, HEMP, Contingency Management, Risk Management

Journal Reference Format:

Osuchukwu, C.L., Meremikwu, B,C., Obaseki, E. \& Onuoha, B \& Unuogu, C.C. (2020): Leveraging on Industrial and Occupational Safety to Enhance the Dwindled National Economy After Ravages Done by COVID-19 Pandemic . Behavioural Informatics, Digital Humanities \& Development Journal Vol 6. No. 1. Pp 69-86. Article DOI No - dx.doi.org/10.22624/AIMS/BHI/V6N2P8

Available online at behaviouralinformaticsjournal.info; https://www.isteams.net/behavioralinformaticsjournal

\section{INTRODUCTION}

Concerns for accidents dates back in history to the industrial revolution of the $18^{\text {th }}$ century, when machines were invented and factories were built and were installed with these machines. Several accidents occurred in the factories resulting in injuries, maiming, incapacitation, and death. People also suffered illnesses from exposure to toxic fumes and gases. These accidents and illnesses occurred because workers were exposed to contact with dangerous moving parts of the machines that had no guards on them, and the factories were poorly lit and inadequately ventilated. In addition, the workers were not properly trained to work on the machines. Meanwhile, the employers were happy with the returns that resulted from increased production at lower cost, caring little about the suffering of the workers, Shell: HSE-MS Training Manuals and Materials. (2001) This situation raised humanitarian issues of people suffering pain and loss of earnings, and families losing their breadwinners. There were, as a result, protests from workers, families, and well-meaning citizens.

Governments, of the then industrialized countries, reacting to the protests, enacted legislation, requiring employers to safe and healthful place of work, pay for medical care, and pay compensation for injuries, disabilities, death, and illnesses that result from work activities. This reaction introduced an economic factor to be considered: it became obvious that it cost money to have accidents. 
Other consequences of accidents at work were lowered morale of employees and damaged reputation of the Company when accidents are frequent, both of which also have economic impacts (Bird, 1969). Researchers found the economic impact of accidents to be far reaching, effecting not only employers who suffered heavy financial loss, also employees and their families, as well as communities and government. Accidents have not seized to occur in our contemporary industrial activities. There are reports of insistent collapsing of building in so many parts of this country, industrial accidents and traffic accidents which seem to have become the order of the day in recent times. The most ugly-recent accident report being the rude news of Dana air plane crash of June $3^{\text {rd }}, 2012$. Researches and experience have shown that accidents do not just happen, but are caused by unsafe acts and unsafe conditions. In view of the above, there is every need for the proper implementation of Health, Safety and Environment Management Systems in our every day industrial activities by the stake holders involved.

\subsection{Accident}

Accidents, as such, are appropriately defined as unwanted occurrences caused by unsafe acts and unsafe conditions resulting in injury or damage, or neither. People are the puzzle: people that act unsafely and create, or allow, unsafe conditions. It is established that people that act thus involved because, they either do not know how to, or could not, perform the task correctly. Some others do not bother to follow rules. Since accidents are caused, they can be prevented. The causes can be identified, and then eliminated through the processes of engineering, education, enforcement, and encouragement, rooted in an effective management system, - the HEALTH, SAFETY and ENVIRONMENT MANAGEMENT SYSTEM (HSE-MS) Shell: HSE-MS Training Manuals and Materials. (2001)

The costs of accidents include Medical, Compensation, Time lost from work by injured, Some men quit when they see serious accidents on job, Economic loss to injurer's family, Lost time by fellow crewmen at time of accident assisting injured, etc. Loss of efficiency due to breakup of crew, Damage of morale tom crew, Cost of breaking in new crewman, Damage to tools and equipment, Time lost by Supervisor, Loss of earning power (wages) 4 to 5 times greater than compensation)

$>$ Spoilage-fire, water, chemical, explosives etc.

$>$ Company's loss of rig time

$>$ Overhead cost (while work was disrupted)

$>$ Miscellaneous-there are many other items of cost that appears one more times with every accident.

Health, Safety and Environment-Management System (HSE-MS).

One effective management system is the Health, Safety and Environment Management System. It is defined as a quality management system for managing risks within the company to assure the protection of its people, assets, and reputation, and the protection of the environment the company operates within. Incorporated in the HSE-MS are the means to meet the requirements of the Company's HSE Statement, Policy and Commitment, including those of continuous improvement and compliance with the law.

\section{Importance of HSE - MS}

Appreciating that there are hazards in its business activities and does not want these to impact on its people, assets, reputation and the environment within which it operates. It has therefore installed HSE - MS for the following stated reasons: We must control our risks. We must be able to demonstrate that we are controlling our risks. Synergy between H, S, E and other business objectives and learn Lessons from past. 


\section{Essential Elements of HSE - MS}

A systematic approach to HSE Management System requires the following elements:

$>$ Demonstrable management leadership and commitment - Management and supervision shall be regarded as being fully committed to HSE by all staff and contractors. They are to be seen as providing a leading role towards constant improvement through leadership and action planning. Management shall regularly review the suitability and effectiveness of the system.

$>\quad$ Policy and strategic objectives - Companies shall have a written HSE policy, covering the group policy element as a minimum. HSE objectives shall be challenging, understood by all and consistently incorporated in policies. In setting objectives, management shall consider the overall risk level of its activities and shall identify those critical operations and installations which require a fully documented demonstration that risks have been reduced to as low as reasonably practicable (ALARP).

$>\quad$ Organization, Responsibilities, Resources, Standards, And Documents - the organization and resources shall be adequate for its purposes. Responsibilities at all levels shall be clearly described, communicated and understood. Staff shall be developed following structured competency assessment and training systems. Preparation, review and distribution of all key reference documentation shall be adequately controlled.

$>\quad$ Hazards and Effects Management Process (HEMP) - the process for those critical operations and installations should include.

i. An inventory of the major hazards to the environment and to the health and safety of people of all the activities, materials, products and services; and

ii. An assessment of the related risks, implementation of measures to control these risks and to recover in case of control failure.

$>\quad$ Planning and Procedures - adequate standards and procedures shall be in place and understood at the appropriate organization levels. Preparation, review and distribution of all key reference documents shall be adequately controlled. HSE standards include: procedures; and

$>\quad$ Work instructions; permit to work; concurrent operations; contractor HSE; business cycle and HSE planning; controlled documentation. Emergency response procedure (including medical emergencies) shall be regularly tested.

$>$ Implementation and Monitoring - HSE performance targets shall be set to ensure progression towards the long-term goals of no harm to people and no damage to the environment. Performance indicators shall be established monitored and results reported in a way that can be externally verified, all HSE incidents and near misses with significant actual or potential consequences shall be thoroughly investigated and reported.

$>\quad$ Audit - scheduled audit program should be in place to review and verify the effectiveness of the management system. It includes audits by auditors independent of the process or facility studies. An audit program will include internal and external audits, external certification. Audit follow up shall be timely, thorough and auditable.

$>$ Review - program (on business plan schedule) of management review of HSE - MS as well as general issues. The objective is to assess suitability and effectiveness of the system. A yearly review of implementation and a 3-yearly review of management system.

\section{HSE-MS Methodology.}

$>\quad$ Identify the business process.

$>$ Break down the process into its constituent activities

$>$ Identify whether activity is HSE critical.

$>$ Establish the Hazard (Effect) Management Objective.

$>$ Identify the methods of meeting these objectives. 
$>$ Select the appropriate controls to provide the necessary assurance.

$>$ Document the HSE-MS process.

\subsection{Applications}

HSE Management System ensures the systematic management of all HSE risks throughout the business. A demonstration that such management systems are in place and working is required. Such demonstration can be through HSE -MS manuals.

A corporate HSE -MS applies a common set of controls to corporate level activities and is evidenced by a series of documents:

1. The HES -MS Manual, which describes the overall approach and requirements of the system.

2. HSE Procedures, which describe what, must be done to meet the requirements of the system.

3. HSE Standards, which describe the performance acceptable to SPDC for the system.

4. HSE Guidelines, which provide additional information to support, items 1 to 3 above.

Every asset or activity required by the corporate HSE -MS to have a sub HSE - MS will also have similar documents as the corporate HSE - MS but will describe issues at the asset or activity level.

$\checkmark$ The Corporate System (as described in its documentation) is considered insufficient to ensure risks at asset or activity level are managed to ALARP,

$\checkmark \quad$ The specific activities in question contain unique HSE risks requiring specific systems (and therefore documents) to ensure the risks are managed to ALARP.

\section{Hazards and Effects Management Process.}

The hazards and effects management process is generally referred to as HEMP. Hazard is defined as the potential to cause harm, ill health or injury, damage to property, plant, products or the environment, production losses or increased liabilities. Hazard should not be confused with hazardous activities (e.g. Drilling). Examples of hazards: Hydrocarbons under pressure, Objects at height, Electricity, Toxic substances, Noise, Radiation, Working at heights.

Effect is defined as either the consequence of not managing a hazard, e.g. loss of control, or the consequence of an unintended release. An effect is usually an adverse effect either on the health or safety of employees or the public. HEMP is therefore, defined as a process for identifying the hazards in an HSE critical activity and the effect, with a view to eliminating them or controlling them to reduce the effect to as low as reasonably practicable. It is central to the effective implementation of the HSE - MS, and is therefore referred to as the heart of on HSE - MS.

Steps in the HEMP Process: The principles of Identify, Assess, Control and Recover are the basis of HEMP.

The principles are applied in the following steps:

Identify Hazards and Potential Effects.

Systematically identify the hazards, the threats and potential hazardous events and effects which may affect, or arise from, a company's operation throughout the total life cycle of the operation.

$\checkmark$ Evaluate (Assess) Risks.

Systematically evaluate (assess) the risks from the identified hazards against accepted screening criteria, taking into account the likelihood of occurrence and the severity of any consequences to employees, assets, the environment and the public. This includes the risks associated with deviation form limits set for environmental and occupational health hazards. 
$\checkmark$ Record Hazards and Effects.

Record all those hazards and effects identified as significant in relation to the screening criteria in one the following documents:

- HSE - MS activities catalogue.

- HSE - MS specification sheets.

- Hazards and effects register.

- HSE critical operations procedures.

- Manual of permitted operations.

These documents will then be included in the HSE - MS Manual.

\section{Compare with Objectives and Performance Criteria.}

Compare the evaluated risks against the detailed HSE objectives and targets for the project or installation. For all cases these targets must be maintained and be consistent with the company policy and strategic objectives. Performance standards at all levels must meet the criteria set in the HSE case which in turn must comply with company's HSE management system.

\section{Establish Risk Reduction Measures.}

Select, evaluate and implement appropriate measures to reduce or eliminate risks. Risk reduction measures include those to prevent or control incidence (i.e. reducing the probability of occurrence) and to mitigate effects (i.e. reducing the consequences). Mitigation measures include steps to prevent escalation of developing abnormal situations and to lessen adverse effects on Health, Safety and the Environment. Risk reduction measures also include Recovery Preparedness Measures, which address emergency procedures as well as restoration and Compensation Procedures to Recover. Record fully the activity/task requirements as in step 3.

Implementation of HEMP: The process can be implemented at any point in the life cycle of a facility or operation. When planning the development of new facilities, reviewing existing facilities, or planning for the abandonment and decommissioning of existing facilities, the focus is on the identification and assessment of hazards and effects that may be avoided reduced or eliminated.

In the operational and maintenance phase, the focus is on control of hazards and effects by procedures and the development and implementation of effective recovery preparedness measures. In the abandonment and decommissioning phases the focus is directed towards safe clean up and rehabilitation. People in operational activities, however, should always be alert to identify new hazards, particularly in non-routine operations.

HSE Risk Assessment: Risk is defined as a function of the probability of occurrence of an undesired event together with a measure of its adverse consequences.

Risk analysis seeks to answer questions such as, how likely and how seriously can things go wrong? What is the potential loss or damage? Or. What can go wrong? How likely is it? What are the impacts?

\subsection{Types of HSE Risks}

Potential loss of life, asset, production, insurance.

Potential damage to health including injury and sickness, environment, asset, reputation.

All types usually manifest in serious financial and adverse consequences. 


\section{Objective of Risk Assessment.}

Risks are assessed to:

- Provide a clear framework in which all available information is used

- Compare alternatives, particularly in the design phase

- Optimize the use of scarce resources, monkey, people, and time

- Meet regulatory requirements.

- Identify potential economic vulnerability

- Identify hazardous situations/procedures

- Provide knowledge of patterns of events and identify critical parts of the operation.

\section{Basic Characteristics of Decision Making Under Risk Assessment.}

a) Risk without benefits is unacceptable.

b) Risk decision can be based on value of the consequences, or the likelihood obtain a positive result.

Approach.

* Estimate likelihood and consequence of undesirable events e.g. fires and explosions.

* Define cost effective risk reduction measures providing a maximum level of safety of personnel and assets.

\section{Procedure To Follow.}

1. Identification of hazards.

2. Quantification of likelihood and consequences.

3. Evaluation of effect on business.

Once a potential hazard has been identified, questions arise with regard to severity. The risk associated with a potentially hazardous event consists of two basic elements:

1. The likelihood of the event.

2. A measure of its adverse consequences. Quantification of both elements is often a useful exercise to form an opinion of the seriousness of the risk. This quantification is often essential with respect to structured decision-making on risk reduction measures.

\section{CONTINGENCY MANAGEMENT.}

The hazards and effects management process notes that the top event when a hazard is released could escalate with disastrous consequences should the barriers in place fail. Recovery preparedness measures were therefore considered necessary to prevent or mitigate the effect of the escalation of the top event. One of such recovery preparedness measures is a contingency management plan. Contingency is defined as an event or situation that might happen in the future, especially one that might cause problems. Such an event could be a disaster event or an emergency. A disaster is defined as a very bad accident that causes great damage or loss of life. An ugly event such as flood or storm that produces suffering or unfortunate consequences is known as disaster.

An emergency situation is a sudden abnormal or unplanned situation, which requires immediate attention and may endanger human life, the reputation. It is a situation that must be dealt with immediately. A contingency management plan is a plan that you make in order to deal with a problem that might happen. It involves anticipating emergencies and planning to control them through making provisions that may have to be applied to contain the event and mitigate the consequences and enable early return to normal operations 


\subsection{Categories of Disasters}

Disasters producing events or activities are:

Enemy-Attack: Damage causing factors of which are blasts, thermal and nuclear radiations, biological and chemical agents. They are usually overt actions, but often with little or no warning.

Sabotage: Fire, explosion, nuclear radiation, biological and chemical agents. Saboteurs are enemies and use enemy tactics; but their acts are covert and without warning.

Natural/Operational: Earthquake, storm, flood, fire, explosion. These are inherent hazards that people are aware of. They may give signs of being about to happen, or give no warning. A common feature is that there may be no warning of imminent danger; there is also the feature that their effects could be devastating.

\subsection{The Need for Planning}

The motto of the Boy Scout movement "be prepared" is worthy of application in the matter of disasters and emergencies, considering that they may give no warning of being about to happen, and usually do not. Disasters are known to occur, and the fact that they have occurred a number of times is a fair indication that they cloud occur again. That and the fact also that they are sudden, fast and with very severe consequences demand that plans should be put in place to avert the undesirable consequences. Making no plans in anticipation of an event usually results in the circumstance is that time is lost during the ad hoe planning for the event; efforts and resources are duplicated; thus involving more cost, much more than would have been required; meanwhile escalation continues, causing more damage and loss of life, adding to the cost of the event.

\subsection{Preparation for Emergency Control}

Every industry, whether it handles dangerous stuff or not needs an emergency control plan. Certain industries have severe operational hazards that are obvious and are generally well controlled, e.g. drilling operations. Some others believe that they are relatively free of the possibility of a crippling catastrophe because they employ no highly flammable materials, or manufacture no highly dangerous products. The truth is that any building housing some number of people may become a site for disaster in the event of some unforeseen panic producing emergency. Much the same basic control measures possible for emergency conditions will generally apply. A sound approach is to plan survival and recovery measures for all installations. Understanding the threatening dangers and knowing how to reduce and control them before the emergency happens can reduce their effect.

Preparation for control has two facets:

* The specific disaster control organization, plans and training, and

* The fundamental organization structure, operational relationships leadership, morale and discipline, and quality of the physical facilities of the concern as established for general operation.

A well organized, smoothly functioning company with adequate and planned facilities will adjust to a new situation more quickly and effectively than would a firm lacking those characteristics. Even so, the planned organization needs to prepare for an emergency because its customary procedures may prove wholly inadequate and too slow to cope with a sudden emergency. When a disaster occurs the special control organization should go into operation immediately. The normal administration would take over even good administrator cannot on the spur of the moment make as good decisions or take effective actions as are possible with careful crews whose services may be invaluable in an emergency. 


\subsection{Planning Concepts.}

Disaster planning is based on the following concepts:

\section{Vulnerability assessment.}

This involves a determination of the categories of disaster and the damage causing factors to which the installation may be exposed, internally and externally. The nature of the operation, plant and equipment, location, products, and employee and community relations, could make a plant vulnerable to explosion, fire, flood, sabotage, or enemy attack.

\section{Surviving planning.}

The planning goal must be realistic, based on a relative rather than absolute safety. It should be the best available. Some installations may be exposed to situations that could result in total destruction, in which cases survival planning is entirely dependent upon the protection of vital records and personnel continuity measures. Other installations may experience moderate to light damage, and must plan for continuity of operations even with greatly reduced capabilities. Realism is assured if planning is for the most serious eventualities and if plans are made for operation under disaster conditions without normal conveniences and hampered by special personnel and morale problems. Planning must be phased with definite planning goals and reasonable achievement dates.

\section{Self Help.}

For large organizations, each installation is responsible for planning and putting into effect measures necessary to assure its survival. They know their operations and vulnerabilities best.

\section{Determination and exploitation of existing capabilities.}

A sound disaster emergency plan utilizes to the maximum the existing operational structure, proven supervisory and technical skills, and material and equipment on hand. Maximum effectiveness is attained when the unknown and variable factors in the situation are reduced to a maximum through prior planning. The disaster organization should not be a substitute for, but an extension of, the organization that has proven effective in routine operations. Personnel who give directions in an emergency should be those from whom others are accustomed to receiving directions. The skill to perform specialized emergency tasks should be derived from professional and vocational interests. Emergency equipment should augment or supplement equipment on hand.

\section{Operational Readiness.}

Only sound plans in a state of operational readiness will increase the probability of survival. Operational readiness implies preparing the plan, training personnel in emergency responsibilities, testing the plans, evaluating the tests, revising the plan as necessary, and constant retesting of the plan to ensure its adequacy and workability in event of disaster. Readiness cannot be accomplished if personnel are not familiar with the contents of the plan and their responsibilities. Therefore, also implied here is the dissemination of information as needed to the individual employee, preferably by his supervisor.

\section{Specific Control Measures.}

\section{Fire}

Since fire can begin from so many causes - processing accidents, poor housekeeping, earthquake, floods, destructive winds, or warfare - fire prevention and protection must receive major attention. This aspect of the programme is in charge of the fire chief, a man who should have had special training in fire prevention and protection, as well as had adequate experience in fire department work. When a fire occurs, it is necessary to take prompt, definite, and correct steps to defend against it. Certain preliminary knowledge, therefore, should be gathered during the period of organizing for the fire protection phase of the disaster control plan. 
The information indicated by the following items, when applied during the training sessions for the fire brigades, for example, will assist in saving valuable time when the need for efficient action is paramount:

a) A plan of the ground and buildings comprising the installation should be obtained.

b) The location of all main control valves process (process equipment, water supply, fuel supply etc.)

c) A plan should be prepared of each available water-supply source (Private and public), such as ponds, Lakes Rivers, water mains, tanks, and pumps with their estimated capacities and available pressure at ground level.

d) Knowledge of first-aid fire-extinguishing equipment, its applications, limitations, and maintenance is essential. All such equipment should be easily reached and identified, and its location in the buildings and on the grounds should be indicated on a ground plan.

e) It is advisable that the director of disaster control acquire information on alarm systems and automatic sprinkler, foam and water-spray or fog systems, even if this equipment may not be installed in the plant at present.

The economic and protective advantages derived from such equipment may encourage his recommending its installation. He should also know the limitations, under emergency conditions, which may exist for the automatic equipment which may have been installed. The fire safety aspect of the plan would include provision for quick evacuation of the building or site. There would be instruction, training, and drills to acquaint staff emergency exits and the routes to them; wardens, men and women, would be selected and ensuring that staff move out orderly and promptly using designated exits; selvage and rescue teams whose function would be to assist injured person to safety as well as move essential equipment and documents to safety, stopping machines and processes and isolating the power supply where appropriate: such equipment and documents must have been previously identified as needing such attention in an emergency.

\section{Floods}

Unlike most other disasters, floods ordinarily do not strike with extreme suddenness. Therefore, there is generally sufficient time to take definite preventive measures once a flood seems imminent. In territories where floods are possible, the vulnerability of the plant should be determined. Plants erected on high properties may be considered safe. Those that are located near rivers or the sea are confronted with the possibility of flood from the over flowing of the river or due to tidal waves or other severe disturbances at sea. On the basis of experience through the previous years, the probable high water mark should be determined. Where flood possibilities exist, preliminary organizational and design precautions should be considered. For example, records and other valuable papers, tool cribs, expensive instruments, and equipment likely to be damaged by water and silt should be located above the previously determined high water mark. The installation of the telephone system should be such that it is reasonably safe from interruption.

Equipment that is needed for returning the plant to operation, such as fuel-driven generating equipment, should be installed in places not apt to be reached by water. Storage tanks located under the probable high water mark (including tanks that are installed underground) should be anchored to prevent floating. Vents should extend above the high water mark to prevent the possibility of the tanks being filled with the floodwaters. Other emergency precautions, such as the storing in places not accessible to flood water, of heaters and a supply of gasoline in safety containers to fuel the auxiliary equipment, should be provided for as promptly as possible. When flood is imminent, all doors, windows and ventilators should be closed and battened down to keep out the water and possible looters. Vents and pipes below the high water mark should be plugged. Tank cars should be moved to higher ground and anchored because they will float when empty, as will portable containers and other buoyant materials. Chemicals that are soluble in water should also be moved above the high water mark. Electric and gas utility services should be shut off at the main line before any water reaches them. Sufficient time before the rising of the floodwaters should be allowed for hot machinery and equipment to cool down so that they will not be damaged by the chilling effect of the water. 
All machined surfaces should be liberally covered with heavy grease, especially around opening to bearings. This should be done also to machines that may not be subject to being under water, inasmuch as dampness will affect them materially. Salvage squads should be asked to remain at the plant if possible. They will be able to continue preventive operations after the plant has been shut down, and they will be ready to take further necessary steps if the flood shows signs of exceeding the estimated high water mark. When the floodwater begins to recede steps should be taken to return the plant to operations by cleaning, disinfecting, heating and drying out of machinery and equipment.

\section{Wind and Thunderstorm}

The first consideration is that the plant and its surrounding and supplementary buildings should be sturdy, which the climatic conditions of the location would suggest at the time the plant was being planned. In situations where there is an extreme exposure to heavy winds, plants should be equipped with storm shutter, at least on the side of the plant where the wind would blow heaviest. Since there is usually some warning of a storm, staff should have instructions to anchor stuff that could be lifted and thrown about by the wind. Having done so, they remain indoors for the duration of the storm. It is important that at the end of the storm, steps be taken to check to ensure that electrical cables are not cut and lying where people could walk into them and be electrocuted.

Persons who are caught outside in a wind or thunderstorm should seek the nearest sturdy structure and lie flat beside it to avoid being struck by flying objects or lightning. Should a fire start, the fire procedure should be initiated. Summarily, the essence of an emergency control plan is to prevent a disaster from resulting in serious consequences. The nature of operations and the location of a plant will usually determine the sort of an emergency it could be exposed to. The right thing to do therefore would be to assess the disaster events a planned project could be exposed to and to build into the structure facilities that would prevent the event, or establish control measures that would minimize the effect of the event should it occur. It should be realized that information, instruction, training and practice alone will make any disaster plan work as expected. Important also is to win the wholehearted cooperation of every employee by getting employees to understand that it as much for their safety and safety of their jobs as it is for the safety of the property of the employers.

\section{LOGISTICS HSE (TRANSPORTATION SAFETY).}

It is on record that the highest numbers of human lives are lost through transportation activities either on land, water or air. The increased number is due to non-adequate policies, plans, procedures, and standards in transportation safety. Transportation Safety is having led down policies, plans, procedures, standard of execution of all transportation activities of an organization; in the safe and efficient movement of goods and personnel from one location to another. The objectives of transportation safety in an organization, amongst others include:

- Safety of personnel, goods (equipment and machinery, through prevention of accidents.

- Effective use of vehicle resources and reduction in personnel exposure.

- Maintenance of uniform standards of practice for SPDC and contractors.

- Top have a single point responsibility for transportation related activities.

\section{Transportation Safety Challenges.}

The challenges facing transportation safety should be looked into by:

$\checkmark$ Treating all logistics as a business process - through proper planning to Implementation, Evaluation of all processes.

$\checkmark$ Attention should be given to the essential safety elements. These elements are:-

$\checkmark$ Resources, Minimization of exposure, Contractors Strategy, Driver Management, Journey Management

- Always subject all transportation activities to HEMP (Hazards and Effective Management Process). 
$\checkmark$ HEMP elements are: Identification of hazards, Assessment of its effect(s), Control measures in place, Recovery Measure in place should the control fails.

$\checkmark \quad$ The knowledge and compliance of rules and regulations in the transportation policies and standards.

$\checkmark$ Showing and living by examples. From the CEO/MD to the ordinary people must obey and live by the led down policies.

$\checkmark$ All organizations should have their own transportation safety plan; otherwise called Journey Management Plan (J/M Plan)

$\checkmark$ Finally, there must be effective communication devices in the vehicle e.g. Radio, IVMS, Microsam etc.

$\checkmark$ subordinates, and for arranging for the briefing of supervisors and drivers.

\section{SAFETY LEGISLATION, POLICIES AND IMPLEMENTATION.}

It is important that persons in industry who Endeavour to inculcate safety awareness and compliance with safety legislation should review and discuss existing relevant safety laws and what compliance implies. This will engender an appreciation of the need for compliance with operational procedure guides and manuals issued by organizations for the performance of specific operations. Safety legislation are enacted for employers to ensure the safety of persons and the protection of assets and the environment, consequently safe operating procedures are developed by responsible employers to ensure compliance with their legal obligation. An understanding of the legal requirement for safe procedures will make for ready compliance with operational procedures.

Management must be aware of the existence of these laws but, with the heavy commitments management usually has for meeting corporate objectives, some management may be inclined to think they should have no direct involvement with safety legislation, having delegated responsibility for safety to some department down the line. This would be wrong. Management needs to understand the requirements and objectives of these laws to be able to readily appreciate safety recommendations and make necessary funds available, and establish appropriate policies that would ensure safety of operations. For production related functions, policies are made, tasks and targets are set, responsibilities assigned, and the performance of departments and individual employees measured constantly, daily, weekly, monthly and yearly, annual programmes are drawn and reviewed daily. These actions are taken to ensure that each employee contributes effectively towards the achievement of the corporate objective. Safety performance needs also to be monitored in like manner that would enhance the chances of achieving the ultimate corporate objective, - maximum profits through maximum production at minimum cost, enabled by production uninterrupted by accidents. Safe production enhances profits, and an effective safety programme is built on a good knowledge of and compliance with safety related legislation

\subsection{Development of Safety Legislation}

Safety legislation, as we have them today, had their origins in governments' response to the protests of early industrial workers and their families because of injuries and deaths to workers at places of work. The transition from manual production in the homes and on the farms -(cottage industries as they were known), to production with machines in factories in the 18th century in England, and in the United States and other industrialized countries in the 19th century, referred to as the Industrial Revolution, brought a new type of work hazard. Men, women and children were explored work in these factories, without training or previous experience. They were exposed to machinery with unguarded moving gear wheels, cutting blades and power operations that continued until shut off, as well as to large concentrations of inherently dangerous chemicals, fumes and dusts; they worked long hours from sunrise to sunset, and the factories were poorly built with inadequate ventilation, lighting, heating, aisle space and sanitation. 
This situation was set for, and resulted in, several accidents in which the employees were seriously injured, maimed or killed. The reaction of the injured employees or families who lost their breadwinners was to claim against the employers at common law, but they had handicaps. In the first place, an employee, who had hopes of going back to his employment on recovery, was not inclined to risk his job by taking his employer to court. There was also the fact that the employer had to be proved negligent and this was not easy since no other employee would be inclined to place his employment in jeopardy testifying in court against his employer. On the other hand, the employer had three strong pleas which were often difficult to overcome: that the employee's negligence contributed to the accident; the employee's fellow worker's fault; or that the employee knew the hazards of the job and assumed the risk when he accepted the job. Apart from the foregoing difficulties, where an employee succeeded in winning his action in court, the award was usually so small that the cost of litigation took almost all of it. This was perceived as an unsatisfactory situation, and employees, their families and other well-meaning influential citizens, protested to government about it.

Governments' reaction to the outcry for help was the enactment of legislation that it was hoped would improve the employees. England, and later some States in America, enacted laws requesting employers to provide safe tools and machinery, and to maintain safe and healthful working conditions. It soon became evident that legislation by itself was not enough. In England, the Factory Commission of 1833 made a survey of conditions in the developing textile factories, and found that earlier factory legislation had been "almost entirely inoperative with respect to the legitimate objects contemplated by it". It therefore recommended the setting up of a professional inspectorate, appointed and paid by the government and responsible for enforcing the law. As a result, the Factory Act of 1833 authorized the king to appoint four persons to be Inspectors of Factories. From these pioneering beginnings, the British Factories Inspectorate initiated a form of government action, which is now to be found in almost every country in the world, and which received international support in 1947 by I.L.O. Convention. Thus, almost every country now has qualified government labour inspectors maintaining organized inspection of work places and working conditions as part of effort to improve health and safety at word.

\subsection{The Factories ACT 1990}

The International Labour Organization, in continuation of its efforts to improve health and safety at work, produced a "Model Code of Safety Regulations for Industrial Establishment[s for the Guidance of Government and Industries". The manual was based on a draft prepared by experts and approved by a Tripartite Technical Committee held in Geneva, in the autumn of 1948, in accordance with a decision of the Governing Body of the International Lobour Office. This code was put in its final form in 1949, and was placed at the disposal of Governments and industries for guidance in framing or revising their own safety regulations. Nigeria, a member of the International Labour Organization, ratified and adopted the relevant International Labour Organization Convention and, in 1955, enacted "An Ordinance to make provision for the health, safety and welfare thereto and connected therewith". This Ordinance came into force on 1st September 1956. It became chapter 66 of the laws of the Federation of Nigeria and Lagos in force on the 1st day of June 1958. On being reviewed by a military regime it became the Factories Decree 1987 with a commencement date of 11th June 1987. It is currently the Factories Act 1990 (Cap. 126).

Objectives: When it was promulgated in 1955 the Ordinance was hailed as a 'workers' charter', because of its expressed objectives. The stated purpose of the decree, which employees recognized as being in their best interests, is 'to provide the legislative frame work to promote, stimulate and encourage high standards of health, safety and welfare in industrial establishments, with the aim to

$\checkmark$ Secure the health, safety and welfare of persons at work;

$\checkmark$ Protect persons, other than persons at work, against risks to health or safety arising out of in connection with the activities of persons at work;

$\checkmark$ Involve everyone, both management and employees, and make them all aware of the importance of safety and health. 
Arrangement: The Factories Act is arranged in eleven parts, each part specifying provision for the achievement of each to the stated objectives.

\section{Part I - Registration of Factories.}

Since factories have to be visited and inspected periodically to ensure compliance with the Factories Act, their existence and location have to be known. For this purpose, the Act in Part I requests that the Director of factories shall keep a register of factories, and that person who were already operating factories before the promulgation of the Act must apply to the Director of factories for the registration of such factories must apply for registration at least six months before the commencement of the actual construction of a building or structure intended to be used as a factory. Any subsequent changes in the particulars furnished with the application for registration are required to be notified promptly to the Director of factories for approval and the amendment of the register of factories.

\section{Part II - Health (General Provision)}

For ensuring the health of employees, the Act, in Part II, prescribes general provisions and minimum standards to be maintained, and specific measures to be taken, in industrial premises with regard to - Cleanliness, Overcrowding, Ventilation, Lighting, Drainage of floors, and Sanitary conveniences. These provisions are emphasized because low standards could affect the health of workers adversely. The emphasis is considered necessary because these are areas that the usually not given due consideration by industrial organizations. In this regard, in addition to the provision for sanitary conveniences in Section 12, there are the Factories (Sanitary Accommodation) Regulations, which stipulate the number of conveniences, the lighting in them, and their construction, location and arrangement where there are male and female employees.

\section{Part III-Safety (General Provisions)}

Part III of the Act stipulates general provisions required to ensure safety in establishments to which the provisions of the Act apply. It requests the fencing of machinery or dangerous parts of machinery, and vessels or sumps containing dangerous liquids, and prescribes steps to be taken to ensure the safety of employees who work on or around machinery. Section 23 specifically requires that employees who work on or with machinery should be trained and supervised by experienced persons. To make sure that plant and equipment do not fail and cause injury and damage, there are provisions requiring that equipment such as hoists and lifts, chains, ropes and lifting tackle, cranes and pressure vessels, which could fail as a result of deterioration from usage or age, are tested at prescribed intervals of time. The tests will determine whether the equipment should continue to be used at its rated capacity, downgraded or removed from service. Precautions, to be taken in places where dangerous fumes are likely to be present, and with respect to explosives or other inflammable dust, gas, vapour or substance, are prescribed in sections 29 and 30 . Sections 35 and 36 require that provision should be made for preventing fire, and for fighting fired that may occur, and that adequate means of escape in case of a fire should be provided and maintained.

\section{Part 1V - Welfare (General Provisions)}

Provisions for welfare of employees at their places of work are detailed in Part IV of the Act. This part requires the provision of drinking water, facilities for washing, accommodation for clothing not worn during working hours, and first-aid facilities. These are required to be adequate and suitable for the use of the employees, and must be maintained. Adequacy in this regard has reference to the number of persons employed. The First Aid Boxes (Prescribed Standards) Order, a subsidiary legislation, specifies what is adequate.

\section{Part V - Health, Safety and Welfare (Special Provision and Regulations).}

In appreciation of the fact that certain operations have health and safety hazards peculiar to them that are of a very injurious nature, the Act in Part $\mathrm{V}$ makes special provisions for inhaling dangerous dusts and fumes, and to prevent these from accumulating in the workroom. It prohibits people eating or drinking in any room where the process give off dust or fume, and require the provision of protective clothing and appliances in any process involving excessive 
exposure to wet or to offensive or injurious substances. Protective clothing and appliances include appropriate gloves, for footwear, goggles, head coverings and overall. A factory Inspector has the power to take samples of what he considers a dangerous substance.

\section{Part VI - Notification And Investigation Of Accidents And Industrial Diseases.}

Part VI of the Act requires that an accident, which occurs in a factory and which causes death or disables any employee for more than 3 days from performing the duties for which he was employed, shall be reported to the Inspectorate by the occupier of the factory. Where an accident, reported as resulting in disablement, eventually results in death, it is required that this development is also reported. Should the accident occur to a person who is not the direct employee of the occupier of the factory, the actual employer is required to promptly report the incident to the occupier who would report it to the Inspectorate. Dangerous occurrences and industrial diseases are required to be reported also. Dangerous occurrences include any special class of explosion, fire, collapse of buildings, accident to machinery or plant, because of the risk of serious bodily injury to persons employed. Industrial diseases are disease or illness that, in the opinion of the Inspectorate, may be contracted by an employed person because of the nature of his employment in a factory, and are so declared. Diseases so declared are listed in the Declaration of Industrial Diseases Notice L.N. 114 of 1956. The object of this requirement is to enable an inquiry to be instituted should it be considered necessary. Failure to report is an offence that attracts a fine of $\mathrm{N1}, 000$ on conviction.

\section{Part VII - Special Applications, Extension And Miscellanceous Provisions.}

Part VII of the Act extends the application of certain sections of the Act to -

1. Other parts of a building, part of which is registered as a factory, if such other parts are used for the purpose of the registered factory;

2. Docks, wharves and quays;

3. Premises in which steam boilers are used.

There is provision for the Minister, if he deems it necessary, to extend provisions of the act to warehouses, premises in which a hoist or lift is used, and work on ships carried out in a harnour or wet dock, building operations undertaken by way of trade or business, works of engineering construction undertaken by way of trade or business. The objective here is to ensure safety of persons engaged in the operations in these premises that by definition are not factories.

\section{Part VIII - General Register, Etc.}

Part VIII requires that factory occupiers shall

a) Keep and maintain a general Register in which they will file the certificate of registration and enter such particulars as washing, white-washing, accidents etc, for inspection by visiting Inspectors of Factories;

b) Post in a prominent position a copy of the Abstract of the Factories Act, notice of the addresses of the Director of Factories and the nearest Inspector, abstract of regulations, all of which shall be in English or any language an Inspector may direct.

\section{Part IX - Administration.}

The Minister, Director of Factories, Inspectors of Factories and other officers, whose appointments are published in the gazette, administer the Act. Every person so appointed is issued a certificate of appointment, which, if required, he presents as his authority for entering any premises to which the Act applies. An Inspector is under obligation not to publish or divulge to any person the details of any manufacturing, commercial or working process that comes to his knowledge in the course of his duties, accept for the purpose of prosecution, Coroner's inquest, or an enquiry under the provision of the Act. An Inspector is expected to treat as confidential the source of any complaint bringing to his notice a contravention of the provisions of the Act. 
The Inspector of Factories is empowered to enter, inspect and examine any factory premises by day or night for enforcing the provisions of the Act. The occupier of every factory, his agents and servants are required to "furnish the means required by an inspector as necessary for any entry, inspection, examination, inquiry or the taking of samples or otherwise for the exercise of his powers under the provisions of this Act in relation to that factory".

Wilfully an inspector, or withholding any information as to who is the occupier of the factory, or concealing or preventing or attempting to conceal or prevent a person from appearing before or being examined by an inspector, is deemed as obstructing an inspector in the execution of his duties under the provisions of the Act. This is an offence that attracts a fine not exceeding $\mathrm{N} 1000$, or imprisonment for a term not exceeding six months, or both such fine and imprisonment.

An inspector has powers of prosecution, conducting or defending before a court any charge, information, complaint or other proceeding arising under the Act or in the discharge of his duty as an inspector. However, in the belief that education, properly backed by enforcement, is the most effective approach, since enforcement through inspections alone will prevent only a few injuries, Inspectors no longer only look for breaches of the law and prosecute defaulters. They have come to accept it as part of their duty to explain what the law intends, as well as to advise as to how its aim can be achieved. There is a continuous responsibility on their part to be alert for anything, whether mentioned in the law or not, which may affect the safety or health of employed persons.

\section{Part X-Offences, Penalties and Legal Proceedings.}

According to part $\mathrm{X}$ and certain sections of the Act, failure to comply with provisions of the Act is a contravention of the law under the Act, and such contravention attracts penalties of varying amounts of fines or imprisonment or both. Usually, it is with regard to duties specifically imposed on the employees, the infraction shall be against the employee.

The Act, in Section 69, subsection 5, states that "Where the offence under the Act is committed by a body corporate, from, cooperative society or other association of individuals.

a) Every director, manager, secretary or other similar officers of the body cooperate;

b) Every partner or officer of the firm;

c) Every person concerned in the management of affairs of the cooperative society or association; or (d) Every person who was purporting to act in such capacity as aforesaid; shall severally be guilty of that offence and liable to be proceeded against in like manner as if he had committed the offence, unless he proves that the act or omission constituting the offence took place without his knowledge consent connivance or neglect. However there is provision that where an occupier or owner of a factory could prove that, whereas he had taken steps to ensure compliance, someone else without his knowledge and defaulted, that person shall be proceeded against as if he were the owner or occupier of the factory.

Penalties are prescribed to ensure compliance since occupiers or owners would not want to be embarrassed by being taken to court, nor would the wish to lose the time and money litigation involves. Nor would the want their business shut down. 


\section{Part XI-General}

The act applies only to factories as defines in the Act, and includes factories belonging to or in the occupation of the government of the federation or of a state.The factory in this regard is defined as," any premises in which or within or which, or within the close or cartilage or precincts of which one person is or more persons are, employed in any process for or incidental to any of the following purposes, namely:

a) The making of any article or part of any article; or

b) The altering, repairing, ornamenting, finishing, cleaning, or washing, or the breaking up or demolition of any article; or

c) The adapting for sale of any of any article, being premises in which, or within the close or cartilage or precincts of which the work is carried on by way of trade or for purpose of gain and to or over which the employer of the person or persons employed therein has the right of access or control;

Section 87, in addition to the premises indicated above; also list other premises where ten or more person are employed as coming under the provision of the Act.

Section 55 states that parts (III), (IV), V (with respect to regulations for health, safety and welfare), VI, IX, X and the provision of Part XI with respect to powers and duties of inspectors and to regulations and orders made under the Act, apply to Docks, Wharfs and Quays. This is with particular regard to the processes of loading, unloading or coaling of any ship in any dock or harbour, and to all machinery and plant used in those processes, but not plant and machinery on board a ship and is the property of the ship owner.

Section 56 extends the provision of parts III, V, VI, VII, IX and XI, with respect to specifically mentioned; to apply to premises in which a steam boiler is used, though not part of a factory.

These extensions of the provision of the Act indicate an effort to bring premises that are considered to contain inherent hazards to life under the supervision of the Inspectorate, in consonance with the stated objectives of the Act.

Safety legislation as we have them today developed as governments' response to protests against injuries and deaths to workers in the factories of the $18^{\text {th }}$ century, and continues to be relevant today. The object was, as it still is today, to provide a safe and health work environment. Almost all, if not all, industrialized countries of the world have their own version of safety legislation patterned after the International Labour Organization's specimen code. Nigeria in that regard has the Factories Decree, 1987 which applies to all factories and specific industrial outfits that are specifically mentioned as coming within its ambit.

The provisions of the Act are absolute and it is an offence not to comply with them. Industry, however, needs to comply even for the reason that preventing accidents has financial and social benefits to be derived. For effective compliance, industries' managers have to understand the laws and their intention, that is, the spirit of the law, based on which a safety policy statement should be developed and disseminated to all levels of employees in an organization. This policy should assign responsibility and accountability and should be endorsed by the chief executive of the organization to give it authority. It is important to realize that the safety professional in an organization is not responsibility of the line management. The safety professional's function is advisory for which his training has equipped him adequately. For the organization to benefit from his expertise, he should be accorded an appropriate position in the outfit that will enable him interact effectively with all levels of management and staff. It is important that all management understand the spirit of safety legislation which will enable them apply safety principles whenever relevant in the processes of the industry to which they belong. Safe operating procedures would thus always be the consideration at every planning stage. 


\section{SUMMARY}

The health, Safety and Environment Management System calls for holistic corrective and proactive measures which mitigate against the effects of undesirable effects which result from accident. It emphasizes on the need for personnels to be oriented on the rudiments of accident prevention which are born out in a rooted knowledge of Hazard identification and analysis, Risk management and Accident contingency management. 


\section{REFERENCE}

1. Bird F. F (1969). Director of Safety and Engineering Services for the Insurance Company of North America

2. Deshmukh L. M (2006). Hazard Identification and Risk Control, Industrial Safety Management. Tata Mc Graw Hill

3. Gigliot and Jason (1984), Security Design for Maximum Protection.

4. Nancy Syverson: Safety Practices in High -Risk industries, wed, 9th November 2002.

5. National Safety Council (USA): Supervisors Safety Manual, $6^{\text {th }}$ Edition.

6. NIGERIA MINISTRY OF LABOUR-Factories Decree, 1987.

7. Osanyingbemi B. A (1987) Basic Occupational Health.

8. Shell: HSE-MS Training Manuals and Materials. (2001)

9. Simmond \& Grimaldi (1993) Safety Management.

10. U.S. Department of Labour - Safety subjects.

11. William Handley (1977),Industrial Safety Handbook, 2nd Edition.

12. www.asse.org

13. www.aiha.org

14. www.bhopal.net

15. www.nsc.org.in 